OPEN ACCESS

Edited by:

Peter Kirsch,

University of Heidelberg, Germany

Reviewed by:

Macià Buades-Rotger,

University of Lübeck, Germany

Sandy Overgaauw,

Leiden University, Netherlands

*Correspondence:

David J. Vinkers info@vinkers-psychiater.n!

Specialty section:

This article was submitted to

Social Cognition,

a section of the journal

Frontiers in Psychiatry

Received: 14 September 2019

Accepted: 22 February 2021

Published: 07 April 2021

Citation:

Vinkers DJ, Van de Vorst M, Hoek HW and Van Os J (2021) Social Defeat, Psychotic Symptoms, and Crime in

Young Caribbean Immigrants to

Rotterdam.

Front. Psychiatry 12:498096. doi: 10.3389/fpsyt.2021.498096

\section{Social Defeat, Psychotic Symptoms, and Crime in Young Caribbean Immigrants to Rotterdam}

\author{
David J. Vinkers ${ }^{1 *}$, Micha Van de Vorst ${ }^{2}$, Hans W. Hoek ${ }^{3,4,5}$ and Jim Van Os ${ }^{6,7,8}$ \\ ${ }^{1}$ School for Mental Health and Neuroscience, Maastricht University, Maastricht, Netherlands, ${ }^{2}$ Psychiaters Maatschap \\ Antillen, Willemstad, Curaçao, ${ }^{3}$ Parnassia Psychiatric Institute, The Hague, Netherlands, ${ }^{4}$ Department of Psychiatry, \\ University of Groningen, University Medical Center Groningen, Groningen, Netherlands, ${ }^{5}$ Mailman School of Public Health, \\ Columbia University, New York, NY, United States, ${ }^{6}$ Department of Psychiatry, UMC Utrecht Brain Centre, University Medical \\ Centre Utrecht, Utrecht University, Utrecht, Netherlands, ${ }^{7}$ Department of Psychiatry and Neuropsychology, School for Mental \\ Health and Neuroscience, Maastricht University Medical Center, Maastricht, Netherlands, ${ }^{8}$ Department of Psychosis Studies, \\ Institute of Psychiatry, Psychology and Neuroscience, King's College London, London, United Kingdom
}

Background: The negative experience of being excluded from the majority group (social defeat) may be associated with psychosis in immigrants. The social defeat hypothesis is supported by the high frequency of perceived discrimination and acculturation problems in psychotic immigrants. In addition, social defeat may lead to crime through social problems such as unemployment, school dropout, a broken family structure, or psychotic symptoms.

Methods: We assessed the association between social defeat and acculturation on the one hand and broadly defined psychotic symptoms and crime on the other in Caribbean immigrants to Rotterdam who are aged 18-24 years. The municipality of Rotterdam provided data about Caribbean immigrants to Rotterdam. Acculturation, social defeat (perceived discrimination, sense of control, and evaluation of self and others), psychotic symptoms, and crime were assessed using online questionnaires.

Results: Social defeat was associated with psychotic symptoms in women ( $\beta=0.614$, $p<0.001$ ). This relation applied particularly to the negative self-perception domain of social defeat. Acculturation was associated with neither social defeat nor psychotic symptoms or crime and did not mediate the association between social defeat and psychosis.

Conclusion: The social defeat hypothesis of psychosis may be gender-specific valid but does not extend to crime.

Keywords: social defeat, acculturation, psychosis, crime, Caribbean, immigrants

\section{INTRODUCTION}

Immigration has been recognized as a risk factor for the development of psychosis since Ødegaard published his landmark study in 1932 (1). The findings of Ødegaard were replicated after World War II in Britain with the emergence of large-scale immigration (2-4). African-Caribbean immigrants were especially found to be at risk of developing psychosis (5-8). Studies in the Netherlands confirmed this increased risk of psychosis in immigrants (9-13). The relative risk of psychosis in immigrants is increased five times higher in immigrants with a dark skin color (14). Psychotic immigrants often feel discriminated, have lost their ties with their own culture, and struggle with social problems (15-19). Immigrants living in neighborhoods where they form 
a minority and have little support from ethnic peers are at the highest risk of a psychosis $(20,21)$. This observation was already made in the 1930's, when Faris and Dunham stated that "the extended isolation of the person with the role of an outcast" and "lack of sufficient self-confidence" were associated with psychosis in immigrants (22).

These findings led to the hypothesis that the increased incidence of psychosis in immigrants is associated with the experience of social defeat $(23,24)$. This social defeat hypothesis posits that the negative experience of being excluded from the majority group is the common denominator of major schizophrenia risk factors such as migration, urban upbringing, childhood trauma, and drug abuse (25).

Social defeat has also been linked to the high crime rate of Caribbean immigrants to Western European countries such as the United Kingdom and the Netherlands $(26,27)$. Caribbean immigrants have the highest crime rate of all population groups in the Netherlands with an annual conviction rate of 100 crimes per 1,000 persons (28). The crime rate on the Dutch Caribbean themselves is, in contrast, $<6$ per 1,000 persons (29). The high crime rate of Caribbean immigrants to the Netherlands has been related to socio-economic and cultural problems, such as school dropout, financial problems, a broken family structure, discrimination, and acculturation problems (30). In general, immigrants have lower crime rates, a phenomenon called the healthy immigrant effect (31). It is believed that the lower crime rate in immigrants is explained by strong social ties and more traditional values (32). Later generations of immigrants lose these traditional cultural values and become more adapted to their host country (33). A weakening of social bonds in immigrants (e.g., dropping out of school and having a lack of attachment to society) may lead to a low self-control and crime $(34,35)$. Social defeat may also increase crime rates in Caribbean immigrants through psychotic symptoms, as this is an independent risk factor for crime $(36,37)$. This is supported by the disproportionately high number of psychotic Caribbean immigrants in forensic psychiatric hospitals in Western Europe (38-41). Psychotic subjects may also be more likely to become victims of violence (42).

Hitherto, the relation between social defeat and psychosis and crime in immigrants has not been studied in a single study. Furthermore, most studies in this topic are casecontrol, which makes it difficult to disentangle the direction of the relationship. We examined if social defeat (perceived discrimination, sense of control, and evaluation of self and others) and acculturation were associated with psychotic symptoms and crime in young Caribbean immigrants to Rotterdam. We hypothesized that both social defeat and acculturation were associated with psychotic symptoms and crime. As there are indications for different pathways in male and female immigrants to the Netherlands (15), we analyzed these groups separately. We hypothesized furthermore that psychotic symptoms themselves were associated with crime.

\section{METHODS}

\section{Participants}

Caribbean immigrants form a well-defined ethnic group with a significantly increased risk of psychotic symptoms and crime (9-13, 38-42). Rotterdam has the largest number of Caribbean immigrants in the Netherlands (28). Caribbean ethnicity was defined, in line with the Dutch Central Bureau of Statistics, as a person with at least one parent born in one of the former Dutch Antilles or Aruba $(28,29)$. In addition, participants were asked if they saw themselves as having a Caribbean ethnicity, a commonly used assessment of ethnic group in the Netherlands. The Municipality of Rotterdam provided addresses of all Caribbean immigrants to Rotterdam aged 18-24 years. Data pertaining to 2015,2016 , and the first half of 2017 were received quarterly. The sampling frame consisted of 2,388 persons. They were sent a written invitation to participate and were offered a 15 -euro gift certificate for participation. In total, 64 participants enrolled and started with the online questionnaire. Eleven questionnaires were omitted because not all questions were answered. In total, 53 participants were included in the study.

\section{Questionnaires} Acculturation

The process of becoming part of a new culture is called acculturation. Acculturation is a dynamic characteristic that develops and changes over time (43). It reflects the degree in which the original culture is retained while adapting to the new one (44). Both a weak and a strong involvement in the original culture has been described as a risk factor for psychosis in immigrants $(45,46)$. For acculturation, the Ethnic and National Identity questionnaire (12 items) was used. This questionnaire has response options ranging from "strongly disagree" (1) to "strongly agree" (5). It assesses ethnic and national affirmation, sense of belonging, and feelings about being a national and ethnic group member. It has a sufficient reliability with a Cronbach alpha higher than 0.8 (44). Acculturation was assessed as Dutch and Antillean cultural acculturation scores, with higher scores indicating a higher degree of involvement in the Dutch or Antillean culture.

\section{Social Defeat}

Social defeat is defined as the negative experience of being excluded from the majority group $(14-16,23,24)$. We assessed social defeat as the total sum score of sense of control and evaluation of self and others minus perceived discrimination. Higher scores on social defeat indicate more experience of social defeat (more discrimination, less control, and negative evaluation of self and others). The subfactors were assessed by the questionnaires from the International Comparative Study of Ethnocultural Youth (ICSEY) $(44,46)$ and the Brief Core Schema Scales (BCSS) (47). The ICSEY is an international project studying the adaptation and integration of immigrant juveniles. The ICSEY questionnaires have been validated for use in the Netherlands (44). The ICSEY perceived discrimination subscale consists of five items about the experience of being treated 
negatively or threatened, with responses ranging from "strongly disagree" (score 1) to "strongly agree" (score 5) with a reliability Cronbach alpha of 0.83 (46). The ICSEY sense of control subscale consists of six items and assesses the feeling of being in control (e.g., "What happens in the future mostly depends on me"), with responses ranging from "strongly disagree" (score 1) to "strongly agree" (score 5).

The BCSS is a 24-item self-report assessment of schemata concerning self and others (47). It has good psychometric properties with an internal consistency of (alpha) 0.78 for evaluation of self and 0.88 for the evaluation of others in nonclinical samples and a median item correlation of 0.78 (47). The scale evaluates four dimensions of self and others: negative-self (six items), positive-self (six items), negative-other (six items), and positive-other (six items). The scale was recoded to give scores about negative evaluation of self and others. The Dutch translation used in the international EUGEI study was used with a 5-point Likert scale with scores ranging from 6 up to 30 (48).

\section{Broadly Defined Psychotic Psychopathology}

Psychotic symptoms were assessed with the Community Assessment of Psychic Experiences (CAPE-42) (49, 50). The CAPE-42 is a validated 42-item self-report questionnaire of psychotic symptoms (51). It has good reliability and validity with intraclass correlation coefficients of $0.62-0.64$ for the positive, negative, and depressive dimensions (49). Each item explores the frequency of the experience on a 4-point scale of "never" (score 1) to "nearly always" (score 4) and the degree of distress associated with this experience on a 4-point scale of "not distressed" (score 1) to "very distressed" (score 4). The CAPE-42 has 20 items of positive psychotic symptoms, 14 items of negative experiences, and 8 items of depressive experiences (49-51). Positive symptoms reflect an excess or distortion of normal functions, e.g., delusions, hallucinations, and disorganized thought. Negative symptoms reflect an absence or loss of normal abilities, such as flat or blunted affect and emotion, lack of motivation, and poverty of speech. Higher scores indicate more symptoms on each scale.

\section{Crime}

Delinquent behavior was assessed using a 25-item selfreport questionnaire, validated in the Netherlands (52). The questionnaire is sensitive for delinquent behavior in juvenile Caribbeans (53). Earlier research showed a satisfactory reliability by comparing the self-reported crime scores with data from the police (54). The questions are about minor and frequently occurring offenses, e.g., fare dodging in public transport, vandalism, and shoplifting, but also for serious and less frequent ones, e.g., burglary, robbery, and hurting someone with a weapon. The offenses include property offenses, vandalism, and violent offenses. A total score was calculated for all crimes. In addition, participants were asked if they ever were arrested, taken to prison, or convicted, but all participants denied this question.

\section{Procedure}

Those who agreed to participate were asked to fill in a consent form and to provide their contact information (email address and telephone number). Participants subsequently received an email containing a link to the online questionnaire. The online questionnaire consisted of $\sim 157$ questions and took about $30 \mathrm{~min}$ to complete. The questionnaire screened acculturation, social defeat, psychosis, and crime. The standing Medical Ethical Committee of Maastricht University Hospital approved the study.

\section{Data Analysis}

We used Stata to analyze the data. The association between psychotic psychopathology (outcome factor) and social defeat, acculturation for the Dutch and Antillean culture, gender, and level of education was assessed with multivariable regression analysis. Level of education was classified as low in case of only lower general secondary education. Gender differences and differences in educational level for associations between social defeat and broad psychotic psychopathology were analyzed with multivariable regression. Also, multivariable regression was used to analyze the association between subfactors of social defeat and broad psychotic psychopathology. A logistic regression analysis was used to analyze the association between self-reported crime, given its zero-inflated distribution, as outcome factor and social defeat, acculturation for the Dutch and Antillean culture, gender, and level of education as independent variables. The Jarque-Bera test was used to assess normality for broad psychotic psychopathology. Heteroscedasticity was analyzed using the Breusch-Pagan/Cook-Weisberg test. Lastly, structural equation modeling was used to analyze mediation effects on the associations as assessed in the described multivariable and logistic regression analysis.

\section{RESULTS}

Table 1 shows the demographic characteristics of the participants. Female participants had a higher score on the CAPE-42 regarding the total, negative, and depressive symptom scores ( $t$-test, $p<0.05$ ).

Table 2 shows the results of the multiple regression analysis for self-reported psychotic symptoms. The results of the regression indicated that the five predictors explained $40.5 \%$ of the variance $\left[R^{2}=0.405, F_{(6,47)}=6.41, p<0.01\right)$. Psychotic psychopathology was predicted by gender $(\beta=-1.13$, $p<0.01)$ and social defeat $(\beta=1.52, p<0.001)$. Acculturation and education were not significantly associated with psychotic symptoms. The association between social defeat and psychotic psychopathology [analyzed in a multivariable regression, $\left.R^{2}=0.768, F_{(5,48)}=39.68, p<0.001\right]$ was negative for male participants $(\beta=-0.207, p<0.05)$ and positive for female participants $(\beta=0.614, p<0.001)$. We found no significant association with acculturation, level of education, length of stay in the Netherlands, or earlier stay in the Netherlands and neighborhood on social defeat, psychotic symptoms, or crime.

The association between subscales of social defeat (self-control, discrimination, perception of others, and selfperception) and psychotic symptomatology was also tested in a multiple regression analysis. The direct effect of social defeat on psychotic symptoms was $0.35(z=3.52,95 \% \mathrm{CI}=0.16-0.55)$, 
TABLE 1 | Demographics of 53 young Caribbean immigrants to Rotterdam.

\begin{tabular}{lrr}
\hline & $\begin{array}{c}\text { Male, } \\
n=18(34.0 \%)\end{array}$ & $\begin{array}{c}\text { Female, } \\
\boldsymbol{n}=\mathbf{3 5}(\mathbf{6 6 . 0} \%)\end{array}$ \\
\hline Place of growing up & & \\
$\quad$ Curaçao & $12(66.7 \%)$ & $14(40.0 \%)$ \\
Bonaire & $2(11.1 \%)$ & $2(5.7 \%)$ \\
Aruba & $3(16.7 \%)$ & $12(34.3 \%)$ \\
Netherlands & $1(5.6 \%)$ & $7(20.0 \%)$ \\
Level of education & & \\
Lower general secondary education & $10(55.6 \%)$ & $18(51.4 \%)$ \\
Higher general secondary education & $8(44.4 \%)$ & $17(48.6 \%)$ \\
Lived in the Netherlands before & & \\
Yes & $5(27.8 \%)$ & $8(22.9 \%)$ \\
No & $13(72.2 \%)$ & $27(77.1 \%)$ \\
Years lived in the Netherlands & $0.88(0.67)$ & $1.28(1.17)$ \\
Social defeat & $17.2(15.3)$ & $18.5(9.5)$ \\
Negative perception of others & $4.8(5.7)$ & $6.3(4.4)$ \\
Negative perception of self & $14.9(8.1)$ & $15.5(5.0)$ \\
No feeling of control & $9.5(2.5)$ & $8.4(2.6)$ \\
Discrimination & $12.1(6.0)$ & $11.7(4.1)$ \\
Psychotic psychopathology (CAPE-42) & $56.8(6.8)$ & $62.3(9.8)$ \\
Acculturation & $35.9(6.2)$ & $33.7(7.1)$ \\
Dutch culture & $11.8(3.4)$ & $10.6(4.4)$ \\
Antillean culture & $24.1(4.5)$ & $23.1(5.1)$ \\
Self-reported crime & $0.78(1.06)$ & $1.09(1.38)$ \\
\hline
\end{tabular}

Continuous measurements are presented as mean with standard deviation.

TABLE 2 | Predictive factors for psychotic psychopathology in 53 young Caribbean immigrants to Rotterdam.

\begin{tabular}{lrlr}
\hline Independent variable & $\boldsymbol{B}$ & $\boldsymbol{p}$ & $\boldsymbol{r}$ \\
\hline Gender & -1.13 & $0.001^{\dagger}$ & 0.286 \\
Level of education & -0.01 & 0.927 & 0.039 \\
Social defeat & 1.52 & $0.000^{\dagger}$ & 0.479 \\
Antillean culture acculturation & -0.13 & 0.280 & -0.022 \\
Dutch culture acculturation & -0.05 & 0.670 & -0.024 \\
\hline
\end{tabular}

${ }^{\dagger}$ Significant for $\alpha=0.05$.

and the indirect effect mediated by acculturation was 0.00 $(z=-0.26,95 \% \mathrm{CI}=-0.02-0.02)$. It was found that selfperception significantly predicted psychotic psychopathology $(\beta=-0.301, p<0.04)$. For all multivariable regression analysis, no assumptions for normality or heteroscedasticity were violated (Jarque-Bera and Breusch-Pagan/Cook-Weisberg, both $p>0.05)$. To avoid multicollinearity, predictive factors with a Pearson correlation bigger than 0.30 were omitted, which was the case for perceived discrimination. A log linear regression analysis was used to test if social defeat, gender, education, and acculturation predicted crime. The likelihood ratio of this model was $\chi^{2}(5, N=53)=-35.79, p=0.88$, indicating no associations were found. Structural equation modeling showed no evidence that the effect of social defeat on psychotic psychopathology was mediated through acculturation.

\section{DISCUSSION}

This study shows that social defeat is associated with psychotic symptoms in young female Caribbean immigrants to the Netherlands. Psychosis has in general a later age of onset and probably a more favorable course in women (55). Subclinical psychotic symptoms are, however, more frequent in young female adults, which is in line with our findings (56). In international studies, there are no significant differences between male and female immigrants regarding the incidence of psychosis (57). In contrast, the risk of psychosis in immigrants to the Netherlands is clearly increased for male as compared to female immigrants (15). This is especially true for Moroccan immigrants to the Netherlands (with a 5-fold increased risk of psychosis in males), but also for Caribbean immigrants (15). The gender gap may be related to more substance abuse, discrimination, and an unfulfilled wish to achieve in the new society $(15,45)$. We could, from our data, not confirm or refute this hypothesis. We found, however, no difference in experienced discrimination between male and female participants.

As the participants have lived in the Netherlands for only a short time $(\sim 1$ year on average), it is difficult to disentangle the temporal relation between social defeat and psychotic symptoms in female participants in this crosssectional study. This relationship was, however, independent of acculturation (regarding both the Dutch and the Antillean cultures), neighborhood, or level of education. Although there are indications that psychosis in immigrants is related to cultural marginalization and a low ethnic density of the neighborhood (58), their temporal relationship remains unclear.

We found a negative association between social defeat and psychosis in male immigrants. It is possible that this is a falsepositive finding, especially regarding the significant relationship in the other direction in female immigrants. On the other hand, male subjects with psychotic symptoms may defensively deny any manifestations of social defeat. It is also possible that our assessment may be too early for male participants to establish an association between social defeat and psychotic symptoms. Other studies show that the time between migration and onset of psychosis is typically several years (56). Hollander found, for example, that the time from migration to first diagnosis was around 3 years for non-refugee migrants (58). Other explanations for this finding may be that the group of male participants was too small or less accurate in the online reporting of social defeat and psychosis variables. The concept of social defeat may also require further clarification and further development, as the classification of social defeat factors may be too crude and too general (59).

Female participants reported more psychotic symptoms (especially depressive and negative symptoms) than did male participants in our study. The reported scores of psychotic symptoms and a negative perception of self were relatively high in both male and female participants as compared to nonimmigrant samples from the general population (44-46, 4951). The relation between social defeat and psychotic symptoms was significantly associated with a negative self-perception, but not with the other subscales of social defeat (discrimination, low self-control, and negative perception of others). This may suggest that internal factors are more important than external 
factors in the relation between social defeat and psychosis. Other studies show that social defeat may be associated with depressive and negative psychotic symptoms through negative schemas and loneliness (60).

Acculturation, level of education, neighborhood, or length of stay in the Netherlands were not associated with social defeat, psychotic symptoms, or crime. Although we did not have a large study group and therefore had limited power, there was sufficient sensitivity to demonstrate a significant association between social defeat and psychosis. Other limitations were that crime was based on self-report and that most participants were female, a population at relatively lower risk for delinquency.

Another important finding of this study is that crime in young Caribbean immigrants was not associated with social defeat, acculturation, or psychotic symptoms. The crime rate of this group in the Netherlands is high, with an annual conviction rate of 100 crimes per 1,000 persons (28). This has been related to socio-economic and cultural problems, among others discrimination and acculturation problems (30). We could, however, not establish this association in this group of Caribbean immigrants. Our participants had to participate in the study themselves and may be therefore biased toward less crime. Immigrants have lower crime rates, a phenomenon called the healthy immigrant effect (31). We did not find a relation with acculturation or social defeat. There are possibly other factors explaining the high crime rate in Caribbean immigrants to the Netherlands. In line with this, we found in an earlier study that psychosis did not explain the increased crime rate of Caribbean immigrants to the Netherlands (38).

In conclusion, we found that social defeat is associated with psychotic symptoms in young female Caribbean immigrants

\section{REFERENCES}

1. Ødegaard Ø. Emigration and insanity. Acta Psychiatr Neurol Scand. (1932) 4:1-206

2. Kiev A. Psychiatric morbidity of West Indian immigrants in an urban group practice. Br J Psychiatry. (1965) 111:51-6. doi: 10.1192/bjp.111. 470.51

3. Hemsi LK. Psychotic morbidity of West Indian immigrants. Soc Psychiatry. (1967) 2:95-100. doi: 10.1007/BF00578322

4. Sharpley M, Hutchinson G, McKenzie K, Murray RM. Understanding the excess of psychosis among the African-Caribbean population in England. Review of current hypotheses. Br J Psychiatry. (2001) 40:s608. doi: 10.1192/bjp.178.40.s60

5. Bhugra D, Leff J, Mallett R, Der G, Corridan B, Rudge S. Incidence and outcome of schizophrenia in Whites, African-Caribbeans and Asians in London. Psychol Med. (1997) 27:791-8. doi: 10.1017/S00332917970 05369

6. Harrison G, Glazebrook C, Brewin J, Cantwell R, Dalkin T, Fox R, et al. Increased incidence of psychotic disorders in migrants from the Caribbean to the United Kingdom. Psychol Med. (1997) 27:799806. doi: 10.1017/S0033291796004643

7. Harrison G, Owens D, Holton A, et al. A prospective study of severe mental disorder in African-Carribean patients. Psychol Med. (1988) 18:64357. doi: $10.1017 /$ S0033291700008321

8. King M, Coker E, Leavey G, Hoare A, Johnson-Sabine E. Incidence of psychotic illness in London: comparison of ethnic groups. BMJ. (1994) 309:1115-9. doi: 10.1136/bmj.309.6962.1115 to the Netherlands. This was especially related to the internal factor of negative self-perception. Our findings are in line with the social defeat hypothesis, which relates social defeat to psychosis in immigrants $(15-19,23-25)$. More research is needed to assess the temporal association between social defeat and psychotic symptoms. There may be other mechanisms explaining psychosis in male and female immigrants. Crime in this group was not associated with social defeat, acculturation, or psychotic symptoms.

\section{DATA AVAILABILITY STATEMENT}

The datasets generated for this study are available on request from the corresponding author.

\section{ETHICS STATEMENT}

The studies involving human participants were reviewed and approved by the METC azM/UM, the medical ethical review committee of Maastricht University, the Netherlands (NL48702.068.14 / METC143017). The patients/participants provided their written informed consent to participate in this study.

\section{AUTHOR CONTRIBUTIONS}

DV, $\mathrm{HH}$, and JO conceptualized the study. DV and MV analyzed the data and drafted the manuscript. MV contributed to the analysis and interpretation of the data. All author critically revised the manuscript and contributed specific expertise.

9. Selten JP, Sijben N. First admission rates for schizophrenia in immigrants to The Netherlands. Soc Psychiatry Psychiatr Epidemiol. (1994) 29:71-7.

10. Selten JP, Slaets JP, Kahn RS. Schizophrenia in surinamese and Dutch antillean immigrants to The Netherlands: evidence of an increased incidence. Psychol Med. (1997) 27:807-11. doi: 10.1017/S00332917970 05199

11. Selten JP, Veen N, Feller W, Blom JD, Schols D, Camoenie W, et al. Incidence of psychotic disorders in immigrant groups to The Netherlands. Br J Psychiatry. (2001) 178:367-72. doi: 10.1192/bjp.17 8.4.367

12. Schrier AC, van de Wetering BJ, Mulder PG, Selten JP. Point prevalence of schizophrenia in immigrant groups in Rotterdam: data from outpatient facilities. Eur Psychiatry. (2001) 16:1626. doi: 10.1016/S0924-9338(01)00558-2

13. Veling W, Selten JP, Veen N, Laan W, Blom JD, Hoek HW. Incidence of schizophrenia among ethnic minorities in the Netherlands: a four-year first-contact study. Schizophr Res. (2006) 86:189-93. doi: 10.1016/j.schres.2006.06.010

14. Cantor-Graae E, Selten JP. Schizophrenia and migration: a meta-analysis and review. Am J Psychiatry. (2005) 162:12-24. doi: 10.1176/appi.ajp.16 2.1 .12

15. Van der Ven, Veling W, Tortelli A, Tarricone I, Berardi D, Bourque F, et al. Evidence of an excessive gender gap in the risk of psychotic disorder among North African immigrants in Europe: a systematic review and meta-analysis. Soc Psychiatry Psychiatr Epidemiol. (2016) 51:16031613. doi: 10.1007/s00127-016-1261-0 
16. Hjern A, Wicks S, Dalman C. Social adversity contributes to high morbidity in psychoses in immigrants - a national cohort study in two generations of Swedish residents. Psychol Med. (2004) 34:102533. doi: 10.1017/S003329170300148X

17. Veling W, Hoek HW, Wiersma D, Mackenbach JP. Ethnic identity and the risk of schizophrenia in ethnic minorities: a case-control study. Schizophr Bull. (2010) 36:1149-56. doi: 10.1093/schbul/sbp032

18. Veling W, Selten JP, Susser E, Laan W, Mackenbach JP, Hoek HW. Discrimination and the incidence of psychotic disorders among ethnic minorities in The Netherlands. Int $J$ Epidemiol. (2007) 36:761-8. doi: 10.1093/ije/dym085

19. Mallett R, Leff J, Bhugra D, Pang D, Zhao JH. Social environment, ethnicity and schizophrenia - a case-control study. Soc Psychiatry Psychiatr Epidemiol. (2002) 37:329-35. doi: 10.1007/s00127-002-0557-4

20. Veling W, Susser E, van Os J, Mackenbach JP, Selten JP, Hoek HW. Ethnic density of neighborhoods and incidence of psychotic disorders among immigrants. Am J Psychiatr. (2008) 165:66-73. doi: 10.1176/appi.ajp.2007.07030423

21. Kirkbride JB, Jones PB. The prevention of schizophrenia - what can we learn from eco-epidemiology? Schizophr Bull. (2011) 37:262-71. doi: 10.1093/schbul/sbq120

22. Faris REL, Dunham HW. Mental Disorders in Urban Areas. Demography of Urban Psychotics With Special Reference to Schizophrenia. Chicago, IL: University of Chicago Press (1939). doi: 10.2307/2 084252

23. Selten JP, Cantor-Graae E. Social defeat: risk factor for schizophrenia? $\mathrm{Br} J$ Psychiatry. (2005) 187:101-2. doi: 10.1192/bjp.187.2.101

24. Van Os J, McGuffin P. Can the social environment cause schizophrenia? $\mathrm{Br} \mathrm{J}$ Psychiatry. (2003) 182:291-2. doi: 10.1192/bjp.182.4.291

25. Selten JP, van der Ven E, Rutten BP, Cantor-Graae E. The social defeat hypothesis of schizophrenia: an update. Schizophr Bull. (2013) 39:11806. doi: 10.1093/schbul/sbt134

26. Fernando S, Ndegwa D, Wilson, M. Forensic Psychiatry, Race, and Culture. London: London Routledge (1998).

27. Van San M, de Boom J, van Wijk A. Verslaafd aan een Flitsende Levensstijl. Criminaliteit van Antilliaanse Rotterdammers. Rotterdam: RISBO/EUR (2007).

28. Central Bureau of Statistics The Netherlands, www.cbs.nl.

29. Central Bureau of Statistics Netherlands Antilles, www.cbs.an.

30. Van San M. Stelen en steken: Delinquent gedrag van Curaçaose jongens in Nederland. Amsterdam: Het Spinhuis (1998).

31. Lutz M, Streb J, Dudeck M. Living conditions influence psychological distress of migrants in long-term imprisonment. Front Psychiatr. (2019) 10:818. doi: 10.3389/fpsyt.2019.00818

32. Chen X, Zhong H. Delinquency and crime among immigrant youthan integrative review of theoretical explanations. Laws. (2013) 2:210232. doi: 10.3390/laws2030210

33. Lilly, JR, Cullen FT, Ball RA. Criminological Theory: Context and Consequences. Thousand Oaks, CA: Sage Publications (1995).

34. Gottfredson MR, Hirschi T. A General Theory of Crime. Stanford, CA: Stanford University Press (1990).

35. Piquero AR, MacDonald J, Dobrin A, Daigle LE, Cullen FT. Self-control, violent offending, and homicide victimization: assessing the general theory of crime. J Quant Criminol. (2005) 21:55-70. doi: 10.1007/s10940-004-1787-2

36. Brennan PA, Mednick SA, Hodgins S. Major mental disorders and criminal violence in a Danish birth cohort. Arch Gen Psychiatry. (2000) 57:494500. doi: 10.1001/archpsyc.57.5.494

37. Walsh E, Buchanan A, Fahy T. Violence and schizophrenia: examining the evidence. Br J Psychiatry. (2002) 180:490-5. doi: 10.1192/bjp.18 0.6 .490

38. Vinkers DJ, Heytel FG, Matroos GM, Hermans KM, Hoek HW. Pre-trial psychiatric reports on antillean suspected offenders in the Netherlands and on the Dutch Antilles. Tijdschr Psychiatr. (2010) 52:745-52.

39. Bhui K, Brown P, Hardie T, Watson JP, Parrott J. African-caribbean men remanded to brixton prison. Br J Psychiatry. (1998) 172:33744. doi: 10.1192/bjp.172.4.337
40. Coid J, Kahtan N, Gault S, Jarman B. Ethnic differences in admissions to secure forensic psychiatry services. Br J Psychiatry. (2000) 177:2417. doi: 10.1192/bjp.177.3.241

41. McGovern D, Cope R. The compulsory detention of males of different ethnic groups with special reference to offender patients. Br J Psychiatry. (1987) 150:505-12 doi: 10.1192/bjp.150.4.505

42. Choe JY, Teplin LA, Abram KM. Perpetration of violence, violent victimization, and severe mental illness: balancing public mental health concerns. Psychiatr Serv. (2008) 59:153-64. doi: 10.1176/ps.2008.59.2.153

43. Veling WA. Schizophrenia among ethnic minorities:social and cultural explanations for the increased incidence of schizophrenia among first-and second-generation immigrants in the Netherlands (Thesis), Erasmus MC, University Medical Center, Rotterdam (2008).

44. Berry JW, Phinney JS, Sam DL, Vedder P. Immigrant Youth in Cultural Transition. Acculturation, Identity, and Adaptation Across National Contexts. New York, NJ: Lawrence Erlbaum Associates (2006). doi: 10.4324/9780415963619

45. Reininghaus UA, Morgan C, Simpson J, Dazzan P, Morgan K, Doody GA, et al. Unemployment, social isolation, achievement-expectation mismatch and psychosis: findings from the AESOP Study. Soc Psychiatry Psychiatr Epidemiol. (2008) 43:743-51. doi: 10.1007/s00127-008-0359-4

46. Phinney JS, Horenczyk G, Liebkind K, Vedder P. Ethnic identity, immigration, and well-being: an international perspective. J Soc Issues. (2001) 57:493-510. doi: 10.1111/0022-4537.00225

47. Fowler D, Freeman D, Smith B, Kuipers E, Bebbington P, Bashforth H, et al. The Brief Core Schema Scales (BCSS): psychometric properties and associations with paranoia and grandiosity in non-clinical and psychosis samples. Psychol Med. (2006) 36:749-59. doi: 10.1017/S00332917060 07355

48. European Network of National Networks studying Gene-Environment Interactions in Schizophrenia (EU-GEI), van Os J, Rutten BP, MyinGermeys I, Delespaul P, Viechtbauer W, et al. Indentifying geneenvironment interactions in schizophrenia: contemporary challenges for integrated, large-scale investigations. Schizophr Bull. (2014) 40:729-36. doi: 10.1093/schbul/sbu069

49. Konings M, Bak M, Hanssen M, van Os J, Krabbendam L. Validity and reliability of the CAPE: a self-report instrument for the measurement of psychotic experiences in the general population. Acta Psychiatr Scand. (2006) 114:55-61. doi: 10.1111/j.1600-0447.2005.00741.x

50. Hanssen M, Bak M, Bijl R, Vollebergh W, van Os J. The incidence and outcome of subclinical psychotic experiences in the general population. Br J Clin Psychol. Eindhoven (2005) 44:181-91. doi: 10.1348/014466505X 29611

51. Van Os J, Hanssen M, Bijl RV, Vollebergh W. Prevalence of psychotic disorder and community level of psychotic symptoms: an urban-rural comparison. Arch Gen Psychiatry. (2001) 58:663-8. doi: 10.1001/archpsyc.58.7.663

52. Van der Laan AM, Blom M, Verwers C, Essers AAM. Jeugddelinquentie: Risico's en Bescherming. Bevindingen uit de WODC Monitor Zelfgerapporteerde Jeugdcriminaliteit. The Hague (2005).

53. Bongers IL, Van Nieuwenhuizen C. Crimineel Gedrag Bij Rotterdamse Antilliaanse Jongeren. Een verkennende Studie Naar de rol van Psychische en Psychiatrische Problematiek. GGzE (2009).

54. Weijters G,Van der Laan AM, Kessels RJ. De overeenstemming tussen zelfgerapporteerde jeugdcriminaliteit en bij de politie bekende jeugdige verdachten. Cahier 2016-3. The Hague: WODC Publications (2016). Available online at: https://repository.wodc.nl/handle/20.500.12832/167

55. Sommer IE, Tiihonen J, van Mourik A, Tanskanen A, Taipale H. The clinical course of schizophrenia in women and men-a nationwide cohort study. NPJ Schizophr. (2020) 6:12. doi: 10.1038/s41537-0200102-z

56. Schultze-Lutter F, Schimmelmann BG, Flückiger R, Michel C. Effects of age and sex on clinical high-risk for psychosis in the community. World $J$ Psychiatry. (2020) 10:101-24. doi: 10.5498/wjp.v10.i5.101

57. Selten JP, Van der Ven E, Termorshuizen F. Migration and psychosis: a meta-analysis of incidence studies. Psychol Med. (2020) 50:303-13. doi: 10.1017/S0033291719000035 
58. Morgan C, Knowles G, Hutchinson G. Migration, ethnicity and psychoses: evidence, models and future directions. World Psychiatry. (2019) 18:247-58. doi: 10.1002/wps. 20655

59. Hollander AC, Dal H, Lewis G, Kirkbride JB, Dalman C. Refugee migration and risk of schizophrenia and other non-affective psychoses: cohort study of 1.3 million people in Sweden. BMJ. (2016) 352:1030. doi: 10.1136/bmj. i 1030

60. Jaya ES, Ascone L, Lincoln TM. Social adversity and psychosis: the mediating role of cognitive vulnerability. Schizophr Bull. (2017) 43:55765. doi: 10.1093/schbul/sbw104
Conflict of Interest: The authors declare that the research was conducted in the absence of any commercial or financial relationships that could be construed as a potential conflict of interest.

Copyright (c) 2021 Vinkers, Van de Vorst, Hoek and Van Os. This is an open-access article distributed under the terms of the Creative Commons Attribution License (CC $B Y)$. The use, distribution or reproduction in other forums is permitted, provided the original author(s) and the copyright owner(s) are credited and that the original publication in this journal is cited, in accordance with accepted academic practice. No use, distribution or reproduction is permitted which does not comply with these terms. 